\title{
Dynamic Effects of Drought on the U.S. Beef Supply Chain
}

\author{
Amanda M. Countryman, Philip L. Paarlberg, and \\ John G. Lee
}

This research employs an agricultural sector model that links seasonal crop production with disaggregated livestock production sectors, in tandem with observed quarterly data on U.S. drought conditions to assess the long term economic implications of drought for U.S beef cattle producers. Short term impacts show increases in feed costs as well as increases in cattle slaughter resulting from drought-induced culling. The price of live cattle decreases in the short run; however, feed prices remain above baseline levels, and beef cattle breeding inventories decline in the long run, leading to fewer calves moving through the supply chain.

Key words: beef sector, cow/calf production, drought, dynamic model, economics, partial equilibrium model

JEL Classifications: Q10, Q15, Q19

\section{Introduction}

Extreme weather events have hit U.S. cow/calf producers hard in recent years. Drought impacted the livestock industry in much of the nation during 2011 and 2012 and continues to be a concern for some regions in the US. While an estimated $14 \%$ of the U.S. is expected to experience severe or extreme drought at any given time (Ding et al. 2011), the widespread nature of drought in 2011 and 2012 impacted crop and livestock supply chains throughout the nation. In 2011, more than $70 \%$ of U.S. crop and livestock production was affected by drought, while the 2012 drought affected more than $67 \%$ of cattle production, and $70-75 \%$ of soybean and corn production

Dr. Amanda M. Countryman is an Assistant Professor in the Department of Agricultural and Resource Economics at Colorado State University. Her research employs computable general equilibrium modeling techniques to investigate the economic implications of international trade policy, focusing specifically on the impacts of trade reform on agriculture. She teaches international agricultural trade and agribusiness management. Prior to joining the faculty at CSU, Amanda was a trade policy economist at the USDA Economic Research Service in Washington, D.C. Dr. Philip L Paarlberg is a Professor in the Agricultural Economics Department at Purdue University. His research interests include the economic impacts of livestock disease outbreaks. His teaching responsibilities cover agricultural policy and international trade. Dr. John G. Lee is a Professor in the Agricultural Economics Department at Purdue University. He primarily researches in the area of natural resource economics. His specialty areas include water resource economics, soil and water conservation policy, and assessment of agricultural and environmental risk. His current research is focused on linking international trade and the environment. This work ranges from the potential impact of livestock diseases to multifuncionality in trade negotiations.

Agricultural and Resource Economics Review 45/3 (December 2016) 459-484

(C) The Author(s) 2016. This is an Open Access article, distributed under the terms of the Creative

Commons Attribution licence (http://creativecommons.org/licenses/by/4.0/), which permits unrestricted re-use, distribution, and reproduction in any medium, provided the original work is 
in the U.S. (USDA 2012). With increasing use of grain for fuel and feed in tandem with weather-induced shocks to production, feed and forage cost and availability have been a concern for beef cattle producers.

While most crop producers have historically had access to government sponsored crop insurance and disaster payments during periods of drought, beef producers have had limited support under most farm bills. However, the Agricultural Act of 2014 included two permanent programs to assist livestock producers during drought events. The first program, Livestock Indemnity Program (LIP), provides benefits to producers for death of animals caused by adverse weather as well as predation by re-introduced species. The second program, Livestock Forage Disaster Program (LFP), provides compensation to livestock producers for grazing losses due to drought or wildfire. LFP payments for drought are set at a maximum of $60 \%$ of monthly feed costs for up to five months. Both programs are designed to cover losses back to October 1, 2011.

Although these two programs provide some potential relief to beef producers, eligibility criteria and program guidelines may not fully compensate beef producers in the event of a prolonged drought. The LIP only covers losses due to death. Thus, there is no coverage for producers that are forced to cull their herds due to escalating feed costs or degraded pasture and range conditions. The LFP is only available for producers in drought designated counties and only covers a portion of feed costs over a five month period. While drought designation is one criterion for LFP, it does not consider the pecuniary impacts of drought through the entire beef, feed and forage market system. For example, a portion of the 2011 drought impact was mitigated by the movement of beef cattle out of, and import of forage into, the drought stricken area. This mitigation strategy was limited in the 2012 drought, given its extensive spatial nature and the continuation of drought conditions in certain areas that persisted since 2011.

This research investigates the effects of the 2011 and 2012 drought on U.S. beef cattle and beef supply chains, while accounting for adjustments by both crop and livestock sectors over an extended time horizon. The objective of this study is to understand how beef producers, processors and consumers are affected by multi-year drought, which extends the drought-relevant literature that primarily focuses on the short-term effects of drought. Specifically, we employ a dynamic partial equilibrium quarterly modeling framework that integrates the U.S. agricultural economy in tandem with observed changes in crop yields (that affect feed prices and availability) and observed drought-induced culling of beef cattle to estimate the drought impacts on U.S. beef cattle production and beef supply chains. Accordingly, our work proceeds as follows. First, we provide a discussion of the relevant literature that assesses the economic impacts of exogenous weather events on the livestock sector in the background section. Second, we describe the economic model we employ and focus on specifications of the beef cattle supply chain. Next, we discuss the drought-related production shocks that we 
calculate for beef cattle and crop sectors. The results section discusses the model-predicted changes in livestock feed prices, changes in beef cattle slaughters and breeding herd inventories, changes in live cattle and beef prices, as well as the welfare effects for U.S. beef producers, processors and consumers.

Finally, a key contribution of this work is to quantify how long the adjustment period can take, given the persistent cost/price squeeze that cattle producers face during a multi-year drought event. Key conclusions from this research indicate that crop markets return towards baseline levels and stabilize more quickly than the disruptions in breeding herd inventory levels, cattle slaughter numbers and prices for cattle and finished beef products prices that deviate from baseline expectations for the entire 8 year period of analysis. Furthermore, cow/calf producers who supply feeder calves to the market are hit harder than producers further along the supply chain as a result of relatively lower feeder cattle prices at the onset of drought pressures.

\section{Previous Research}

There is a rich literature to assess the economic effects of drought in the US, which is largely comprised of regional and state-specific drought studies. Drought can be a localized occurrence, or can affect large regions, as is the case for the 2011 and 2012 drought that persisted throughout much of the U.S. Several studies provide insight into the state-level effects of drought in different time periods. Furthermore, the persistence of drought in the U.S. gave rise to economic studies on the effects of drought on crop yields to understand how crop production responds to drought pressures (Boubacar 2012; and Westcott and Jewison 2013). Diersen et al. (2002 and 2003) used a state-level Input-Output (I-0) model to find an estimated $\$ 1.4$ billion in economy-wide losses in South Dakota resulting from drought in 2002, while the Food and Agricultural Policy Research Institute at the University of Missouri estimated $\$ 251$ million in drought-related direct losses in the agricultural sector in 2002, accounting for losses for both crop and livestock sectors. Additional state-level research includes studies of drought from 1998-2000 in Georgia (Georgia Department of Natural Resources 2001), drought in 2001 and 2002 in Oklahoma (Arndt 2002), and the 2005 drought in Illinois (Changnon and Knapp 2006). Researchers from Texas A\&M Agrilife Extension have conducted a variety of regional and state-level studies of drought in the state of Texas (Richardson et al. 2013, Anderson et al. 2011, Berger 2011, Jones et al. 2001, Kaase et al. 2007, Young et al. 2006 and 2007). Annual economic impact estimates of Drought in Texas range from $\$ 316$ million in 2002 to $\$ 7.6$ billion in 2011 (Fannin 2011). While the aforementioned findings are not directly comparable to our results, they provide strong, worthwhile reference points to understand the overall drought effects on agriculture for various years at regional and state levels. 
Furthermore, it is important to note that estimates for regional and state drought impacts are smoothed when considering the effects of drought on the entire U.S. (Ding et al. 2011). Additionally, the price effects of drought may lead to economic gains if price increases compensate for the production losses associated with drought. For example, crop producer effects of drought include the changes in returns on sales as well as the value of the crop loss due to drought (Ding et al. 2011). Leister et al. (2015) conclude that while the sales increases in crop sectors did not compensate for drought-related crop losses in 2011, their model-predicted price increases in 2012 were large enough to result in a net welfare gain for crop producers at the national level in 2012. Dhoubhadel et al. (2015) employ a stochastic equilibrium displacement model (EDM) to understand the potential effects of waiving the U.S. Environmental Protection Agency (EPA) Renewable Fuel Standard (RFS) mandate on livestock and crop sectors in the context of crop-related drought shocks for 2012. This work is a valuable contribution to the drought-related literature; yet fails to account for the drought-induced culling that occurred in both 2011 and 2012 which is of critical importance when assessing drought impacts on the beef supply chain.

While crops are continually more resistant to drought over time $\mathrm{Yu}$ and Babcock 2010), cattle producers have struggled with shortages of pasture and other feed sources and the ensuing higher feed costs. Drought conditions in 2011 and 2012 caused beef producers to make adjustments to herd inventories that have long term impacts on the U.S. beef cattle sector (Richardson et al. 2013, Fannin 2012 and Wallander et al. 2013). Research on the short term effects of drought shows decreases in livestock productivity and significant losses for both producers and consumers (Anderson et al. 2012, Bauman et al. 2013, Guidry and Pruitt 2012, Henderson 2012, Wang et al. 2013, Watkins 2012). The existing drought-related literature primarily focuses on the short term impacts of drought on agriculture, yet livestock market adjustments to exogenous shocks require proper accounting of the dynamic adjustment process in the livestock supply chain (Dorfman and Lastrapes 1996, Gramig and Horan 2011). Bastian et al. (2006), Ding et al. (2011) and Anderson et al. (2012) raise the point that drought can cause long term impacts on crop and livestock production which can last for multiple years due to lagged effects, and evidence shows that consecutive, multi-year droughts are more detrimental than shortterm weather shocks, or one-off droughts (Ranjan 2013). These factors further support the need to consider drought impacts in a multi-year, dynamic framework. Such effects have been observed as beef and cattle prices rose in 2013 and 2014. Leister et al. (2015) quantify the effects of the 2011 and 2012 drought on U.S. crop and livestock sectors in a dynamic framework while focusing on national level welfare effects on producers and consumers. This research extends their work to further assess the effects of drought on U.S. beef cattle producers by investigating drought impacts throughout the beef supply chain. 
Our research acknowledges that the effects of market shocks such as drought are not distributed symmetrically along the supply chain (Floyd 1965, Gardner 1975, Heien 1980, Holloway 1991). Two observations from the literature regarding market shocks along the supply chain are relevant to the drought discussion. One is that as input prices change, output prices at the next higher level along the supply chain change as well. Such effects are known in the international trade literature as Stolper-Samuelson or Jones Magnification effects (Dixit and Norman 1980). The second observation is that the market with the more inelastic input supply absorbs a greater proportion of the adjustment, as is shown in our results for drought effects on the beef sector. Accordingly, we employ an integrated agricultural model that allows for the quantification of drought effects on beef producers, processors, and consumers.

In addition to regional and state-level drought studies, there is a variety of work that assesses drought effects at the national level in Canada, Australia and Spain (Agriculture and Agri-Food Canada 2013, Banerjee et al. 2013, Horridge et al. 2005, Jenkins 2013, Kulshreshtha et al. 2003). Similar to many state-level studies, Jenkins (2013) employs an I-O model to assess the drought effects associated with climate change in Spain over an extended time horizon. Alternatively, Horridge et al. (2005) and Banerjee et al. (2013) employ computable general equilibrium (CGE) frameworks to assess the economy-wide effects of drought in Australia. While both studies significantly contribute to the drought-related literature, our decision to employ a dynamic partial equilibrium model rather than a CGE framework stems from our detailed quarterly sectoral modeling and specific parameter estimates that are applied throughout the beef marketing channel.

Another important drought-relevant body of research includes studies of the impacts on developing country producers and consumers, who are affected differently by drought than economic agents in developed nations (Julca 2012; Kusunose and Lybbert 2014; Lawson and Kasirye 2013, Mwakaje 2013, Verner and Breisinger 2013). Additionally, research efforts that augment the aforementioned studies aim to assess the relationship between drought and conflict in developing countries (Maystadt 2014, Jia, 2013). The research regarding the economic implications of drought provides a rich literature on various aspects of the topic. Our study contributes to this body of work by specifically investigating how the U.S. beef supply chain has been affected by multi-year drought. To accomplish this, we employ a dynamic modeling framework that accounts for the seasonal nature of agricultural production and integrates crop and livestock sectors, with key findings indicating that the largest economic losses in the beef sector occur in subsequent periods after the presence of drought.

\section{Economic Model}

This analysis employs a dynamic partial equilibrium model that determines changes in prices and quantities relative to baseline values for U.S. crops, 
livestock and livestock products in response to production shocks from drought conditions. The model is solved relative to values from the annual USDA baseline and then converted to quarterly values using seasonal adjustment factors. ${ }^{1}$ Livestock and crop drought effects are calculated by comparing forecasts from the spring of 2011 before the drought began to actual outcomes for crop yields and cattle slaughter. Agricultural sectors modeled in this framework include coarse grains, wheat, rice, soybeans, soybean meal, soybean oil, forage and pasture sectors that are inputs for animal agriculture sectors including cattle, hogs, poultry, lamb and sheep, eggs and dairy. Animal sectors are linked to animal processing sectors and final goods for consumption include beef, pork, poultry meat, lamb and sheep meat, dairy products, eggs, rice, coarse grains, wheat and soybean oil (Paarlberg et al. 2008). The framework has the structure of a Specific-Factors model with perfect competition where producers and consumers are price-takers that maximize well-defined objective functions. Consumers maximize a well-defined, homothetic utility function given income and prices, which defines the per-capita demand functions for final goods. Producers maximize profit given a well-defined, constant-returns-to-scale production function. The factors of production include mobile factors, primary factors and intermediate goods that are sector-specific, as well as land that is used for crop production and pasture for livestock. Calculated marketing margins are used to vertically link farm prices, wholesale prices and retail prices for final goods. The model is solved by satisfying market-clearing conditions for prices and quantities. This analysis employs the logarithmic differential version of the integrated agricultural model, where results for changes from the baseline for production and consumption are driven by a suite of parameters. The key parameters in the model include sector-specific revenue shares, livestock-feed balance calculators, and several sets of elasticities, which are detailed in Paarlberg et al. (2008).

Revenue shares by sector are determined by dividing cost-of-production data by production revenue. In crop sectors, applicable government payments are included in revenue calculations. Crop sectors overall have relatively even allocations of exogenous inputs, land, and the residual cost of capital and management, while the feed costs comprise the major revenue share for live animal sectors, followed by the residual return to capital and management. Revenue shares for feed ingredients are derived from the livestock-feed balances, which calculate feed use on a per-animal basis by species and production phase. The livestock-feed balance calculators link the stocks and flow of animals to available feed supplies throughout the supply chain. Animal costs comprise the majority of revenue for meat industries, leaving relatively low returns to capital and management.

\footnotetext{
1 A full, detailed description of the model and sector linkages is described in Paarlberg et al. (2008).
} 
The cross-price effects of retail demand are non-negative, indicating that commodities are substitutes. One key exception is that we employ inelastic own-price elasticity estimates for meat, while the aforementioned authors assumed elastic demands for meat. Consistent with the literature on meat demand elasticity estimates, pork is the most sensitive to price changes in the model with an elasticity of -0.9 , followed by beef $(-0.8)$ and poultry $(-0.7)$ (Brester and Shroeder 1995, Tonsor and Marsh 2007).

The substitution elasticities for meat and feed use affect derived demand behaviors that determine commodity outputs, and values used in this work are consistent with the literature (Paarlberg et al. 2008). Substitution elasticities determine the substitutability of feedstuffs given changes in prices. In most cases, substitution elasticities are close to 1 , indicating that the cost shares of feed ingredients are relatively stable with minor substitutions given price changes. However, the substitution elasticity for forage in beef cattle is elastic, which allows for the replacement of forage by concentrates, thereby reducing the cost share of forages in beef cattle rations in the presence of drought. This modeling framework is ideal for the analysis of drought effects along the beef supply chain given its dynamic structure and accounting for changes along integrated agricultural supply chains.

For this analysis, further description of the model structure for the beef and beef cattle supply chain is needed. Consumers are described by the differential equation form of per capita demand which consists of own and cross price elasticities, as previously described. For beef, the own price elasticity is -0.8 and comes from an average across several estimates for the beef demand elasticity, while the cross-price elasticities for pork and poultry are relatively low. Beef production and the derived demand for slaughter cattle are described by differential equations obtained from a mixed complementarity problem similar to the structure presented in Sanyal and Jones (1982). Key parameters are unit revenue shares and substitution elasticities. Unit revenue shares are calculated from the Annual Survey of Manufactures (U.S. Census Bureau). Substitution elasticities are based on MacDonald and Ollinger (2001).

The model explicitly tracks livestock going through the production system over time. Cattle have a production cycle that spans longer than one quarter. Beef cattle are finished and slaughtered five quarters after birth, after moving through the phases of the production process. Calves are born according to the level of the breeding cow inventory. ${ }^{2}$ Calves are weaned 6 months after birth and are not fed any creep rations (feed supplements in addition to milk) prior to weaning. After weaning, calves spend 3 months in background

\footnotetext{
2 It is important to recognize that calving rates are approximately $90 \%$ on average in the U.S., and that there is a death loss for calves (approximately 5\%) and cows as well (approximately $1 \%$ ). The model does not explicitly include a calving rate as a percentage of the cow herd or a death loss for calves or cows, as results are reported as logarithmic changes from the baseline for a given scenario.
} 
lots, 3 months in grower lots, and 3 months in a feedlot for finishing. Whether or not a cow is held and used for breeding depends on two factors including the relative profitability of producing calves for future sale plus the expected value of the cow versus the value of selling the cow for slaughter in the current period (Rosen 1987). The breeding cow inventory is a function of the expected return of retaining a cow for breeding (including the value of the cow plus the expected value of future calves) as well as the previous quarter's inventory, since cow inventories take time to rebuild. The timing of calving is also included in the model. NASS reports indicate that approximately 70 percent of calves in the U.S. are born in the first half of the year; accordingly, it is assumed that 35 percent of cows calve from January to March, 35 percent from April to June, 15 percent from July to September, and 15 percent from October to December. Finally, the number of bulls is exogenous, as these inventories remain relatively constant, and we do not vary the bull inventory under this drought scenario.

Breeding and replacement decisions reflect previous livestock inventories, salvage values and the expected relative profitability of producing animals or animal products for future sale. Cow herd inventories at various gestation phases adjust endogenously, given changes in input prices and expected returns. Cow/calf producers are assumed to set expectations for future returns based on the returns in the previous quarter. The changes in calf and weaning cattle inventories endogenously adjust as well, in response to cow herd inventory adjustments through time. Declines in cattle prices as well as rising feed costs cause cow/calf operators to reduce breeding cow inventory which in turn produces fewer calves and market cattle for slaughter several quarters later. Wheat, coarse grains, soybean meal, and forage and pasture are available for livestock feed and each growth stage has unique derived input demands for feed (Paarlberg et al. 2008). Animal production generates derived demands for each feedstuff. The total feed demand for grain, forage, wheat, and soybean meal consumption are calculated for each stage of production. The feed rations for each growth stage are described in detail in Paarlberg et al. (2008) and are based on information from Kellems and Church (2002), Jurgens (1978), and Field and Taylor (2003). Feed demands for cows are based on feed input prices and dietary requirements of a cow's annual production cycle, where each cow spends one quarter each in trimester I, trimester II, trimester III, and postpartum. ${ }^{3}$ Heifer feed requirements are modeled similarly, and depend on growth stage, the production cycle once a heifer is bred, and feed prices. The differential form of derived demand depends on unit revenue shares and substitution elasticities. Unit revenue shares for the feed stuffs are calculated using feed

\footnotetext{
3 Trimester refers to 3 months of pregnancy, where trimester I includes months 1-3 of pregnancy, trimester II includes months 4-6 of pregnancy and trimester III includes months 7-9 of pregnancy. Postpartum refers to the three months following calving.
} 
use per head from feed rations along with feed prices and the cattle price. Revenue shares for other inputs come from ERS Cost of Production data. Substitution elasticities are generated using a Pseudo-data technique described in McKinzie, Paarlberg, and Huerta (1986). Estimated values are in the neighborhood of 1 indicating little variation in feed ration composition.

Crop production by type occurs at set times of the year and then becomes carry-in stocks in subsequent quarters until a new crop is harvested. Acreage allocations for future crops are decided in the January-March quarter of each year based on expected net returns for each crop at harvest, which is equal to the prices from previous harvests plus any government payments. Rice is harvested in the third quarter, soybeans are harvested in the fourth quarter, coarse grains are harvested in quarters 3 and 4 , and forage and pasture production occurs in quarters 2 and 3.

\section{Description of Shocks for Crops and Livestock in 2011 and 2012}

Shocks to both livestock and crop production sectors follow Leister et al. (2015). Changes from the base for crop production, except for forage and pasture, are derived from the USDA World Agricultural Supply and Demand Estimates (WASDE) Report. Changes in pasture and forage as well as the effects on livestock slaughter in 2011 and 2012 are derived from data provided by the Livestock Marketing Information Center (LMIC). Exogenous shocks to crops are administered during the corresponding harvest quarter (s) for each crop sector. Shocks are based on the differences between expected yield in the initial WASDE report for the year and realized yield. Yield is used as the metric for drought effects because yield is the most strongly affected by drought and initial yield used in WASDE is a historical trend. Therefore, any forecast error for yields is embedded in the calculated reductions presented here. Noteworthy differences between trend and realized yields occurred within crop sectors, which leads to changes in commodity prices (Table 1). The largest commodity shocks are for spring wheat and spring coarse grains. Yield for spring wheat was $20 \%$ lower in 2011 than expectations based on trend, but was more than $21 \%$ higher in 2012 because there was ample rain during the 2012 season in the northern plains. Spring coarse grain yield decreased by 7\% in 2011 and by $26 \%$ in 2012 .

Changes in pasture and forage yields are derived from data provided by the Livestock Marketing Information Center (LMIC). Compared to trend yields, yield data reported by the LMIC for all hay types decreased by 6\% in 2011 and decreased by $15 \%$ in 2012 . The decrease in forage and pasture yield is especially relevant for cow/calf producers since this is the primary feed input used on cow/calf operations.

Drought effects on livestock slaughter in 2011 and 2012 are based on LMIC data and projections. The baseline version of the model relies on LMIC cattle slaughter and cattle inventory data and projections from before the drought. The projections used in this analysis were constructed in early 2011 and are 
Table 1. Quarterly percentage change shocks by U.S. commodity

\begin{tabular}{|c|c|c|c|c|c|c|c|c|c|c|c|}
\hline \multirow[b]{2}{*}{ Year } & \multirow[b]{2}{*}{ Quarter } & \multicolumn{10}{|c|}{ Shocks by Commodity ${ }^{1}$} \\
\hline & & $\begin{array}{l}\text { Winter } \\
\text { Wheat }\end{array}$ & $\begin{array}{l}\text { Spring } \\
\text { Wheat }\end{array}$ & $\begin{array}{l}\text { Winter } \\
\text { Coarse } \\
\text { Grains }\end{array}$ & $\begin{array}{l}\text { Spring } \\
\text { Coarse } \\
\text { Grains }\end{array}$ & Rice & Soybeans & $\begin{array}{l}\text { Winter } \\
\text { Forage }\end{array}$ & $\begin{array}{l}\text { Spring } \\
\text { Forage }\end{array}$ & $\begin{array}{c}\text { Finished } \\
\text { Beef } \\
\text { Cattle }\end{array}$ & $\begin{array}{c}\text { BkgdBeef } \\
\text { Cattle }\end{array}$ \\
\hline \multirow[t]{4}{*}{2011} & I & 0 & 0 & 0 & 0 & 0 & 0 & 0 & 0 & 0 & 0 \\
\hline & II & 5.2 & 0 & 0 & 0 & 0 & 0 & -5.6 & 0 & 5.1 & -4.9 \\
\hline & III & 0 & -20.4 & -0.6 & 0 & 0.5 & 0 & 0 & -5.6 & 4.2 & -3.1 \\
\hline & IV & 0 & 0 & 0 & -7.0 & 0 & -4.4 & 0 & 0 & 2.9 & -0.7 \\
\hline \multirow[t]{4}{*}{2012} & I & 0 & 0 & 0 & 0 & 0 & 0 & 0 & 0 & -0.1 & -0.6 \\
\hline & II & -1.1 & 0 & 0 & 0 & 0 & 0 & -14.8 & 0 & 5.3 & -6.5 \\
\hline & III & 0 & 21.7 & -1.2 & 0 & 3.1 & 0 & 0 & -14.8 & 2.4 & -2.4 \\
\hline & IV & 0 & 0 & 0 & -25.7 & 0 & -9.8 & 0 & 0 & 3.2 & -1.3 \\
\hline
\end{tabular}

${ }^{1}$ Exogenous percentage change shocks to national crop production for each sector are introduced in the harvest quarter. Shocks are based on the differences between yields in the World Agricultural Demand and Supply Estimates (WASDE) report issued prior to crop years 2011 and 2012 (May) and yields given in the January reports after crops have been harvested to capture the difference between the anticipated yield and the realized yield.

Source: Leister et al. (2015). 
treated as the anticipated levels of cattle slaughter. Comparison of cattle slaughter for observed data in 2011 and 2012 relative to the projection suggest unanticipated slaughter in all quarters (except the first quarter of 2012). Drought induced slaughter of lighter cattle occurs in the second through fourth quarter of 2011. The increased slaughter in 2011 is largest in the second quarter and falls in the third and fourth quarter. The data from the first quarter of 2012 suggest that beef cattle producers held cattle in the hope of better crop and pasture conditions; however, drought induced slaughter resumed when conditions did not improve in 2012. The increase in cattle slaughter must come from lighter backgrounder ${ }^{4}$ cattle being slaughtered early (Bkgd Beef Cattle, Table 1). Therefore, there are corresponding decreases in the supply of backgrounder beef cattle flowing into the next quarter. The percentage changes vary slightly, but the total head decrease for backgrounder cattle is the same as the increase in number of head for finished beef cattle.

\section{Results}

Drought in 2011 and 2012 caused an increase in livestock feed costs as a result of reduced crop production. Higher feed costs led to reductions in the livestock breeding inventory as cow/calf producers culled cows when faced with a persistent cost/price squeeze due to prolonged drought conditions. Unanticipated cattle slaughter, both finished and culled cattle, put downward pressure on short term cattle prices and accelerated the breeding herd reduction. As a result of biological lags in cattle production, dynamic drought effects persist well beyond the drought years.

Cow/calf producers are affected by changes in the cost and availability of feedstuffs; primarily forage and pasture. The magnitudes of changes in feedstuff prices are reported in Figure 1. The initial drought effects on forage and pasture are price increases resulting from the reduction in yields in the second quarter of 2011 (Table 1) which is in line with USDA Outlook reports that expected crop price increases following continued drought (Jekanowski and Vocke 2013, and ERS U.S. Drought in 2012: Farm and Food Impacts). The largest difference between baseline and model-predicted forage prices reached nearly $\$ 80 / \mathrm{mt}$ in the second quarter of 2013 . The price of coarse grains increased steadily until the third quarter of 2012, when the expected price is $\$ 75 / \mathrm{mt}$ higher than the baseline. While there was a slight decrease in the change in coarse grains prices in the fourth quarter of 2012 (the harvest quarter), coarse grains prices reached a peak in the third quarter of 2013 at $\$ 141 / \mathrm{mt}$ higher than the baseline price for that quarter. Subsequently, modelpredicted prices of coarse grains fall toward baseline levels beginning in

\footnotetext{
4 Backgrounder cattle refer to feeder calves weighing 675-900 pounds. Backgrounders are sent to finishing, which comprises cattle weighing 900-1200 pounds.
} 


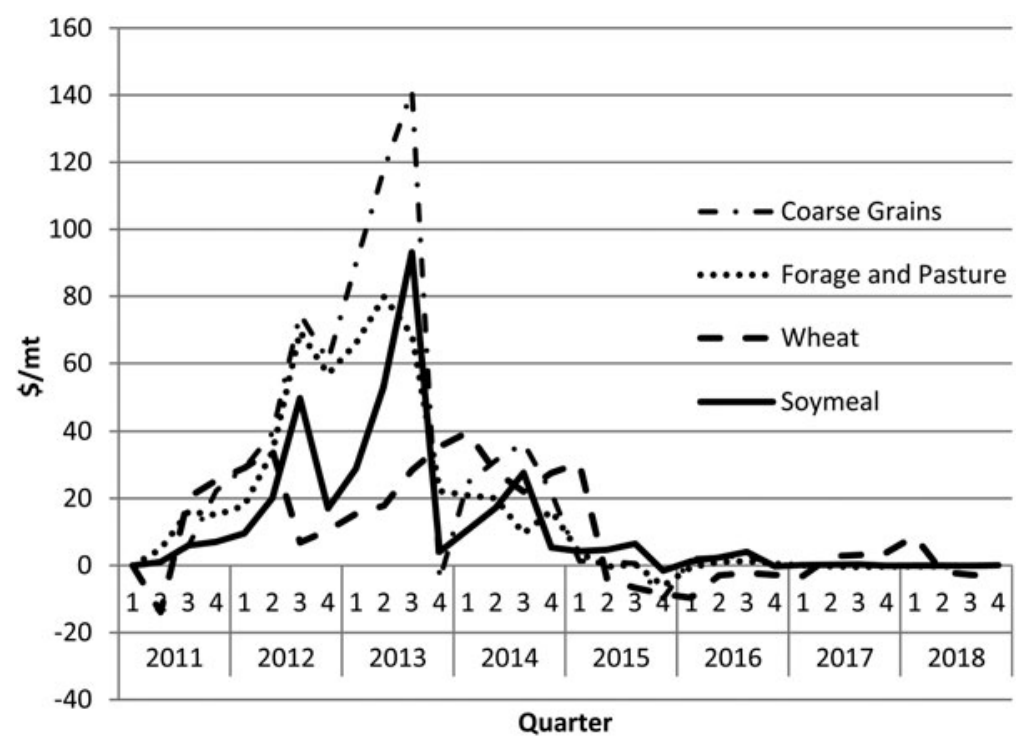

Figure 1. Change in U.S. livestock feed prices ${ }^{1}$

${ }^{1}$ The magnitudes of crop price changes and trajectories between baseline and the model calculated prices are measured by dollars per metric ton for each crop sector.

2014, and reach the baseline in the fourth quarter of 2016. The change in the price of soymeal follows that of coarse grains, yet by a smaller magnitude, and the changes in the wheat price are muted relative to those of coarse grains, forage and pasture. Despite the drought, winter wheat yield increased in the second quarter of 2011 and spring wheat yield increased in the third quarter of 2012.

Cattle producer responses to the drought, resulting from changes in expected returns throughout the supply chain, led to a decrease in beef cattle breeding herd inventories that correspond to a decrease in the supply of calves moving through the supply chain over time and fewer market cattle available for future slaughter. Furthermore, the onset of the drought caused further increases in cattle slaughter by sending lighter calves to market. As expected, returns to beef cattle decrease, and inventories adjust accordingly. As illustrated by Figure 2, beef cattle inventories declined over time until inventories fall to nearly 2 million head less than baseline levels in the first quarter of 2014, which is a $6 \%$ decrease in total inventory. Expected returns began to rise after the first quarter of 2014, and herd inventories are built back up over time, yet do not reach baseline levels by the end of the 8 year period of analysis. This indicates that the effects of the 2011 and 2012 drought are expected to continue for several years as producers adjust their operations in response to changes in the market induced by drought impacts. 


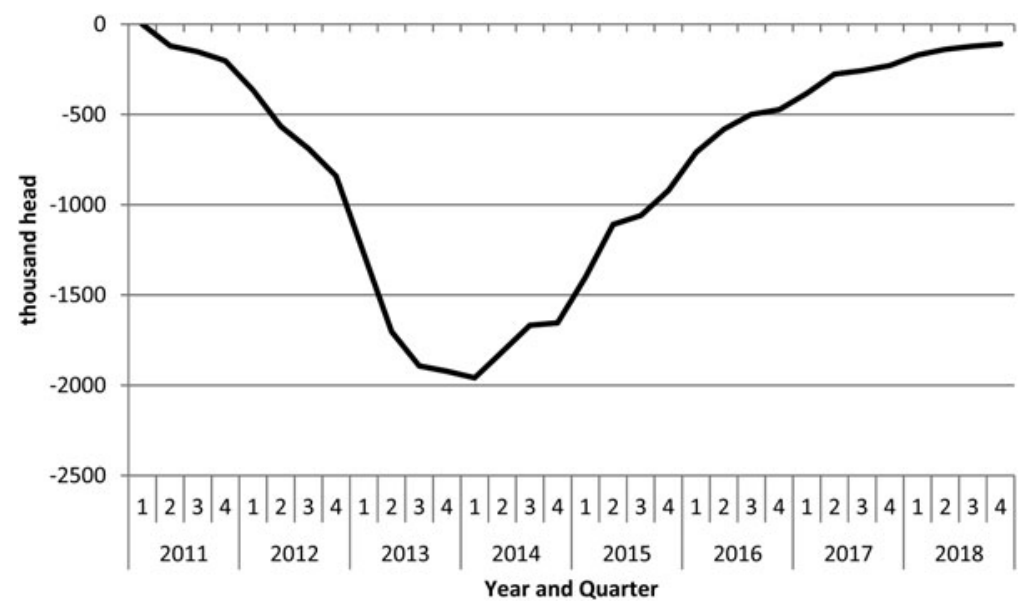

Figure 2. Change in U.S. beef cattle breeding herd inventories ${ }^{1}$

${ }^{1}$ The magnitudes of beef cattle breeding herd inventory changes between baseline and the model calculated inventory levels are measured by thousand head of cattle.

The changes in cattle slaughter vary over the first few years of the series, as shown in Figure 3. There are increases in the number of cattle slaughtered as a result of drought induced culling, which primarily correspond to increases in the costs of forage and pasture and other feedstuffs during the drought years



Figure 3. Change in U.S. cattle slaughter ${ }^{1}$

${ }^{1}$ The magnitudes of beef cattle breeding herd inventory changes between baseline and the model calculated inventory levels are measured by thousand head of cattle. 
2011 and 2012. Model-predicted slaughter was 378,000 head more than baseline slaughter in the second quarter of 2011 as a result of drought induced culling. Slaughter numbers returned to near baseline levels as producers hoped for better conditions in the following year; however, drought induced culling resumed in the second quarter of 2012 when conditions did not improve. The second quarter of 2012 saw an increase in slaughter of 262,000 head more than the baseline for that quarter, while the third quarter of 2012 shows slaughter at 345,000 head below baseline. Slaughter returns to near baseline levels in the fourth quarter of 2012, then decreases from the first quarter in 2013 when the availability of calves in the market is reduced as a result of declining breeding inventories. The expected quantity of cattle slaughtered increases after the third quarter of 2014, as breeding inventories are built back up over time.

The changes in the market price for feeder and finished cattle as well as wholesale and retail beef are illustrated in Figure 4 and are a mirror image of the changes in cattle slaughter numbers. The decline in the 2011 and 2012 finished beef cattle price corresponds to the increase in slaughter cattle sent to market as a result of the drought. The second quarters of both 2011 and 2012 saw large increases in cattle slaughter and the finished beef cattle price is $\$ 13 /$ cwt and $\$ 10 /$ cwt lower than the baseline for the second quarters of

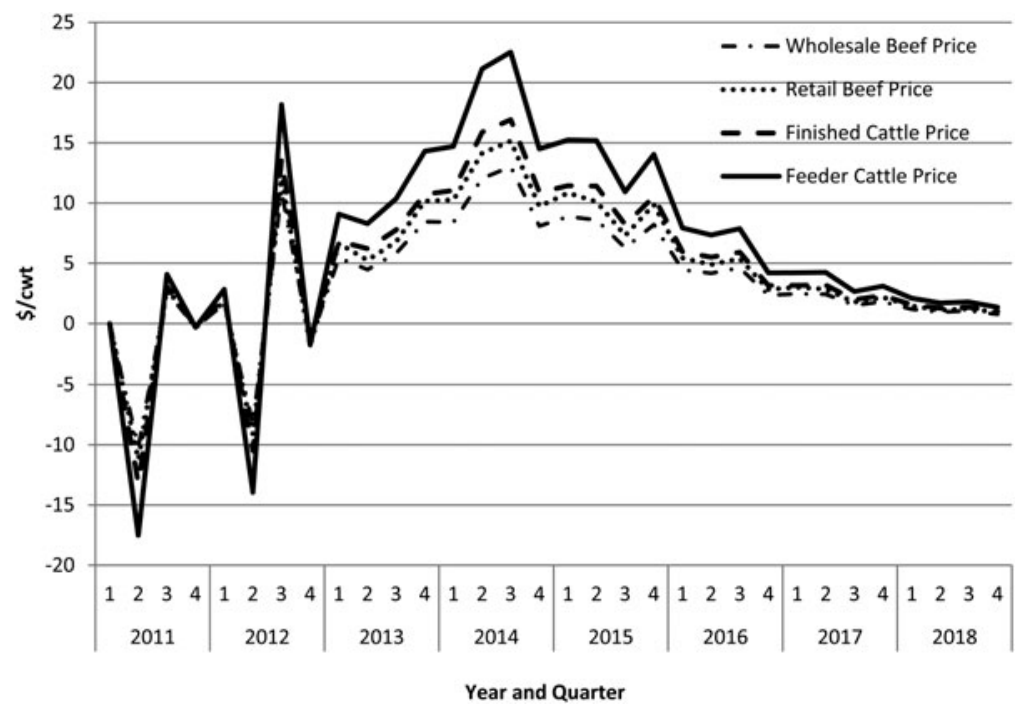

Figure 4. Change in prices for U.S. feeder calves, finished cattle, wholesale and retail beef ${ }^{1}$

${ }^{1}$ The magnitudes of price changes and trajectories between baseline and the model calculated prices are measured by dollars per hundredweight for feeder calves, finished steers, wholesale beef and retail beef. 
2011 and 2012, respectively. There is a jump in the finished beef cattle price to more than $\$ 14 /$ cwt above baseline in the third quarter of 2012, when cattle slaughter had declined to well below baseline levels. As cattle inventories tighten and the number of head slaughtered decreases, starting in 2013, the expected finished beef cattle price rose to nearly $\$ 16 /$ cwt above the baseline in the third quarter of 2014. Again, as model-predicted inventories begin to be rebuilt beginning in the fourth quarter of 2014, more calves are available to move through the market, cattle slaughter begins to increase, and the finished beef cattle price returns toward the baseline but does not reach baseline levels by the fourth quarter of 2018 .

As live cattle move through the market from feeding to finishing, cattle prices are relatively less volatile because supply becomes less inelastic as one moves through the supply chain. Therefore the magnitudes of prices changes are smaller for finished cattle producers than cow/calf operators supplying feeder calves to market. The changes in the expected price of beef feeder calves relative to baseline expectations based on historical trend follow a similar path as the changes in finished beef cattle prices, but are amplified (Figure 4). Feeder cattle prices adjust more as a result of drought pressures because calf supplies are more inelastic than are supplies of cattle already being fed. As relative prices change, the drought effects are augmented for feeder calf producers, which puts further downward pressure on feeder calf prices when relative prices fall, yet feeder cattle producers benefit when prices rise and margins grow by a larger magnitude relative to that for finished cattle. Predicted feeder cattle prices fall to $\$ 17.5 / \mathrm{cwt}$ below baseline expectations in the second quarter of 2011, then return to baseline and slightly higher than baseline prices until falling to $\$ 14 /$ cwt below the base in the second quarter of 2012. Predicted feeder calf prices then rise to $\$ 18.2$ / cwt higher than the baseline in the fourth quarter of 2012. Feeder prices continue to rise, reaching a peak of $\$ 22.5 / \mathrm{cwt}$ above the base in the third quarter of 2014. Just as finished prices begin to fall in 2015, predicted feeder calf prices move toward baseline levels over time to the end of the eight year period of analysis. Overall, changes in the price of feeder calves indicates that feeder calf producers are hardest hit along the supply chain when prices fall, yet benefit more than finished cattle producers when live cattle prices rise.

Wholesale and retail prices for beef follow a similar path as that of live cattle prices but the difference between model-predicted prices and the baseline are muted relative to the differences in live cattle prices (Figure 4). Model-predicted prices for wholesale and retail beef in the second quarter of 2011 are $\$ 2.6 / \mathrm{cwt}$ and $\$ 2.9 /$ cwt below the baseline, respectively. Predicted prices are below baseline levels in the second quarter of 2012 as well when the wholesale beef price is $\$ 8.3 / \mathrm{cwt}$ below baseline and the retail price of beef is $\$ 9.1 / \mathrm{cwt}$ below baseline. Wholesale and retail beef prices spike in the third quarter of 2012 at $\$ 11 /$ cwt and $\$ 12 /$ cwt above baseline, respectively, before falling to near baseline levels in the subsequent quarter. Model-predicted wholesale and retail beef prices rise beginning in the first quarter of 2013 and reach a 
peak in the third quarter of 2014 when wholesale and retail beef prices are $\$ 13 /$ cwt and $\$ 15 /$ cwt above baseline, respectively. Just as is the case for live cattle prices, wholesale and retail beef prices move toward baseline levels in the end of 2014 and nearly reach the baseline at the end of the eight year period of analysis.

We can further assess how beef producers are affected by drought by considering the changes in producer returns relative to the baseline, which are calculated as sales returns minus the variable cost of production in a given quarter. Returns to finished beef cattle producers, on a per hundred weight basis, decrease as a result of drought and are below baseline levels from 2011 until the fourth quarter of 2013 (Figure 5). This three year period of decreased returns corresponds with high feed prices and the resulting increases in cattle slaughter that cause lower live cattle prices during this time. Returns to finished beef cattle producers reach a low of $\$ 33 /$ cwt below the baseline in the second quarter of 2013. Returns exceed the baseline in the fourth quarter of 2014 , peaking at $\$ 13 /$ cwt above the baseline in the fourth quarter of 2015. This increase in returns is caused by higher live cattle prices when slaughter numbers are below the baseline, again corresponding to a smaller breeding herd inventory with fewer beef calves available. Returns remain at levels above the baseline for the remainder of the period of analysis, yet approach baseline levels at the end of the timeframe considered.

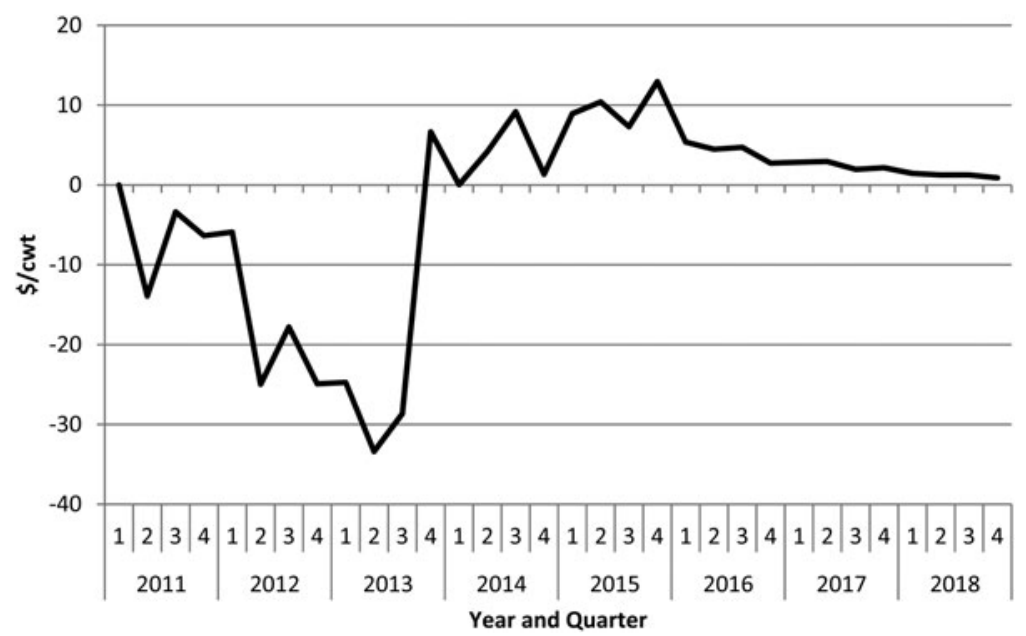

\section{Figure 5. Change in returns to U.S. beef cattle producers ${ }^{1}$}

${ }^{1}$ The magnitudes of changes in returns to beef cattle producers between baseline and the model calculated values are sales returns minus the variable cost of production measured by dollars per hundred weight. 
The effects on beef producers can further be put into context when considering the total value of the changes in welfare for finished beef cattle producers as a result of the drought. We measure changes in producer welfare as the annual value of returns for finished beef cattle producers, processors and retail suppliers under the drought scenario relative to baseline levels for returns (Table 2). Model results indicate relatively large changes in returns for finished beef cattle producers in 2011-2013. The first drought year shows that producer returns are $\$ 1.5$ billion below the baseline, while returns are even lower in 2012 and 2013, equaling $\$ 4.6$ and nearly $\$ 4.8$ billion, respectively. While returns to finished beef cattle producers are above baseline levels for 2014-2018 when live cattle prices are relatively high, the net effect over the eight year period of analysis is an overall loss in producer welfare. The total change in returns to finished beef cattle producers is equal to $\$ 5.9$ billion below baseline returns. Changes in welfare for beef processors are nearly $\$ 300$ million higher than the baseline in 2011, yet are below the baseline for the remainder of the timeframe analyzed. Welfare for beef processors is most negatively affected in 2014 and 2015 when expected returns to processors are more than $\$ 1$ billion below baseline each year. While finished beef cattle producers have a positive welfare change during this time, packers are negatively affected by paying higher prices for beef cattle. The total effect on processors is a $\$ 3.7$ billion decrease in returns over the eight year period of analysis. The value added for beef at retail is also negatively affected during the 8 year period of analysis. The retail value added for beef is $\$ 280.2$ million above the baseline in 2011 , yet is below baseline for the remainder of the timeframe analyzed. Similar to processors, beef retail suppliers are most negatively affected in 2014 and 2015 when the expected value of retail beef supplies are $\$ 1.6$ billion and $\$ 1.2$ billion below baseline, respectively. The total loss in value added for beef retail suppliers is nearly $\$ 4.7$ billion. Consumers also lose as a result of the drought, and have a negative change in welfare by paying higher prices for beef. Economic welfare of consumers is measured by consumer surplus, which is the difference between what consumers are willing to pay and what they must pay for each unit consumed. The change in consumer surplus is equal to the difference in the monetary value between what consumers were paying for agricultural products according to the baseline, before the drought, compared to what they must pay given the model-predicted price increases caused by drought. Consumers are hardest hit during the first four years after the onset of the drought. The overall decrease in consumer surplus for all commodities included in the model relative to the baseline is $\$ 110.9$ billion from 20112018. Of that total, the consumer surplus loss from higher beef prices is $\$ 8.8$ billion. As is the case for producers, consumers will bear the cost of the 2012 and 2013 drought for several years into the future.

To test the sensitivity of model-predicted results to continued drought pressures beyond the two-year drought analyzed in this study, an assumed 2013 drought was considered, and is detailed in the Appendix. Overall, 
Table 2. Changes in welfare from drought in 2011 and 2012 for U.S. beef producers, processors and consumers

\begin{tabular}{lccccccccc}
\hline & $\mathbf{2 0 1 1}$ & $\mathbf{2 0 1 2}$ & million dollars & $\mathbf{2 0 1 4}$ & $\mathbf{2 0 1 5}$ & $\mathbf{2 0 1 6}$ & $\mathbf{2 0 1 7}$ & $\mathbf{2 0 1 8}$ & Total \\
\hline Beef Cattle Producer Returns & -1560.8 & -4629 & -4769 & 720.8 & 2306.8 & 1061.5 & 639.6 & 324.2 & -5905.9 \\
Beef Processor Returns & 294.9 & -99.1 & -755.9 & -1318.3 & -1053.1 & -565.1 & -301.3 & -153.4 & -3951.3 \\
Retail Beef Supplier Value & 280.2 & -130.3 & -877.0 & -1569.2 & -1228.3 & -648.1 & -338.9 & -171.4 & -4683 \\
Total Consumer Surplus & 593.3 & -186.2 & -1668.4 & -2909.8 & -2378.8 & -1217.1 & -668.4 & -331.9 & -8767.3 \\
\hline
\end{tabular}

${ }^{1}$ The welfare impacts on beef cattle producers and beef processors by year are measured by the change in returns to management and capital relative to the baseline measures in millions of U.S. dollars. The total welfare impact is the sum of the annual changes in returns.

${ }^{2}$ Estimates of the drought induced loss in consumer surplus for beef by year, relative to the baseline are measured in millions of U.S dollars. The total welfare impact is the sum of the annual changes in returns. 
continued drought in 2013 results in an amplification of the effects on key variables in the beef sector beginning in 2013 and causes an extension in the time it takes to return towards the baseline. As a result of extended drought pressure into 2013, herd size reductions are intensified, causing increased tightening of cattle supplies, decreased slaughter numbers as fewer market cattle are available for slaughter, and corresponding higher prices for finished cattle given three consecutive years of drought. Under both the two year and three year drought scenarios, baseline levels are not achieved by the end of the period of analysis (2018).

\section{Conclusions}

This research focuses on the effects of drought on the U.S. beef marketing chain and accordingly considers drought-related shocks in both crop and beef production sectors in a dynamic modeling framework to fully assess drought impacts. This work accounts for both the changes in feed costs, and beef cattle prices throughout the marketing chain, while accounting for the availability of cattle moving through the supply chain to calculate the drought effects on U.S. beef cattle producers, processors and consumers. This work investigates the total national effects of the 2011 and 2012 drought and recognizes that regional and statewide droughts can have sizeable economic impacts on producers in areas that are directly affected, which may not be evident in the national-level results. Therefore, we provide national estimates to supplement the valuable work that has investigated drought impacts at state and regional levels.

The largest drought impacts on beef cattle supply chains occur in the third and fourth year after the onset of drought, yet effects persist for six years after the 2011 and 2012 drought-related shocks. Feed prices take less time to stabilize, with the largest price increases for feedstuffs occurring in the third year after the onset of drought. Feed costs return to near baseline levels in the second quarter of 2015, and remain relatively stable through the end of 2018. All in all, while model-predicted livestock feed prices stabilize in slightly more than 2 years after the drought, the effects on breeding inventories, finished cattle slaughter, and finished cattle prices persist for 6 years until baseline expectations are nearly resumed at the end of the period of analysis (2018).

The long term welfare effects include substantial losses in returns to beef cattle producers and processors. Drought induced welfare reductions in the beef production sector include estimated losses to beef cattle producers ranging from $\$ 1.6$ billion in 2011 to nearly $\$ 4.8$ billion in 2013 resulting from model-predicted escalating feed costs and depressed live cattle prices and the ensuing cost/price squeeze. Initially beef processors, retail suppliers and consumers benefit as cattle prices fall by more than beef prices. However, decreased U.S. beef cattle inventories in later years cause beef processors to lose from reductions in slaughter numbers in the long run in 
tandem with higher prices of beef cattle. Beef processor welfare is $\$ 4.0$ billion lower over the 8 year timeframe as a result of drought, while beef retail suppliers experience a loss of $\$ 4.7$ billion. Consumers also bear the burden of the drought. Consumer surplus losses are highest from 2012 to 2014, corresponding to high prices in crop sectors, and the total welfare loss to consumers for all commodities included in the model is nearly $\$ 111$ billion over the 8 year period of analysis.

Although the 2014 Farm Bill includes two permanent programs (LIP and LFP) designed to compensate livestock producers in designated drought areas, the results from this study illustrate the shortcomings of these programs. The LIP and LFP disaster assistance programs do not fully compensate beef producers for increased feed and forage costs during an extended drought. Nor do these programs provide compensation to beef producers that are forced to cull their herd, due to the cost/price squeeze, and receive depressed live animal prices. While the LIP and LFP offer some assistance to qualified producers, this economic assessment of an extended drought identifies changes in beef prices and feed costs that impact crop and livestock producers throughout the United States. That is, the economic impact of a multi-year drought extends well beyond just the drought designated area. In addition, the prolonged economic effects of drought will continue to be experienced by U.S. beef cattle producers, processors, suppliers and consumers for several years to come.

\section{References}

Agriculture and Agri-Food Canada. "Lessons Learned from the Canadian Drought Years 2001 and 2002."

Anderson, D.P., J.M. Welch and J. Robinson. 2012. "Agricultural Impacts of Texas's Driest Year on Record." AAEA Choices 27(3).

Arndt, D.S. 2002. "The Oklahoma Drought of 2001-2002." Oklahoma Climatological Survey Climate Event Summary ES 2002-02.

Banerjee, O., R. Bark, J. Connor, and N.D. Crossman. 2013. "An Ecosystem Services Approach to Estimating Economic Losses Associated with Drought." Ecological Economics (91): 19-27.

Bastian, C.T., S. Mooney, A.M. Nagler, J.P. Hewlett, S.I. Paisley, M.A. Smith, W.M. Frasier, and W. Umberger. 2006. "Ranchers Diverse in their Drought Management Strategies." Western Economics Forum V(2): 1-8.

Bauman, A., C. Goemans, J. Pritchett, and D. Thilmany. 2013. "Estimating the Economic and Social Impacts from the Drought in Southern Colorado." Journal of Contemporary Water Research\& Education Issue 151, August.

Boubacar, I. 2012. "The Effects of Drought on Crop Yields and Yield Variability: An Economic Assessment." International Journal of Economics and Finance (4): 51-60.

Brester, G.W., and T.C. Shroeder. 1995. "The Impacts of Brand and Generic Advertising on Meat Demand." American Journal of Agricultural Economics (77): 969-79.

Changnon, Jr, S.A., and H.V. Knapp. 2006. "The 2005 Illinois Drought: Chapter 7, Information/ Educational Material 2006-3, Illinois State Water Survey, A Division of the Illinois Department of Natural Resources, available at: http://www.isws.illinois.edu/pubdoc/ IEM/ISWSIEM2006-03.pdf 
Dhoubhadel, S.D., A.M. Azzam, and M.C. Stockton. 2015. "The Impact of Biofuels Policy and Drought on the U.S. Grain and Livestock Markets." Journal of Agricultural and Applied Economics 47: Forthcoming.

Diersen, M.A., and G. Taylor. 2003. "Examining Economic Impact and Recovery in South Dakota from the 2002 Drought." Economics Staff Paper, December, Department of Economics, South Dakota State University, South Dakota.

Diersen, M.A., G. Taylor, and A. May. 2002. "Direct and Indirect Effects of Drought on South Dakota's Economy." Economics Commentator, 432, August 26.

Ding, Y., M.J. Hayes, and M. Widhalm. 2011. "Measuring Economic Impacts of Drought: A Review and Discussion." Disaster Prevention and Management 20(4): 434-446.

Dixit, A.K. and V. Norman. Theory of International Trade. Welwyn, UK: Cambridge University Press, 1980.

Dorfman, J.H. and W.D. Lastrapes. 1996. "The Dynamic Responses of Crop and Livestock Prices to Money-Supply Shocks: A Bayesian Analysis Using Long-Run Identifying Restrictions." American Journal of Agricultural and Resource Economics 78(3): 530-541.

Fannin, B. 2012. "Updated 2011 Texas Agricultural Drought Losses Total \$7.62 billion." TexasAgriLife Extension Service. Available at: http://today.agrilife.org/2012/03/21/ updated-2011-texas-agricultural-drought-losses-total-7-62-billion/

Field, T.G., and R.E. Taylor. Beef Production and Management, 4th Edition. Upper Saddle River, NJ: Prentice Hall, 2003.

Floyd, J.E. 1965. "The Effects of Farm Price Supports on the Return to Land and Labor in Agriculture." Journal of Political Economy 73: 48-58.

Gardner, B.L. 1975. "The Farm-Retail Price Spread in a Competitive Food Industry." American Journal of Agricultural Economics 57(3): 399-409.

Gramig, B.M. and R.D. Horan. 2011. "Jointly determined livestock disease dynamics and decentralized economic behavior." Australian Journal of Agricultural and Resource Economics 55(3): 393-410.

Guidry, M. and J.R. Pruitt. 2012. "Damages to Louisiana Agriculture from Natural Disasters." AAEA Choices 27(3).

Georgia Department of Natural Resources. 2001. "1998-2000 Georgia Drought Report.” Environmental Protection Division, Georgia. Available at: http://www.socioeconimpacts. org/documents/sei_252.pdf

Horridge, M., J. Madden, and G. Wittwer. 2005. "The Impact of the 2002-2003 Drought on Australia." Journal of Policy Modeling (27): 285-308.

Heien, D.M. 1980. "Markup Pricing in a Dynamic Model of the Food Industry." American Journal of Agricultural Economics 62(1): 10-18.

Henderson, J., and N. Kauffman. 2012. "Initial Impacts of the 2012 Drought. The Main Street Economist Agricultural and Rural Analysis." Federal Reserve Bank of Kansas City Issue 3.

Holloway, G.J. 1991. "The Farm-Retail Price Spread in an Imperfectly Competitive Food Industry." American Journal of Agricultural Economics 73(4): 979-989

Jekanowski, M. and G. Vocke. 2013. "Crop Outlook Reflects Near-Term Prices and Longer Term Market Trends." USDA Economic Research Service, Amber Waves.

Jia, R. 2013. "Weather Shocks, Sweet Potatoes and Peasant Revolts in Historical China." The Economic Journal (124): 92-118.

Julca, A. 2012. "Natural Disasters with Un-Natural Effects: Why?" Journal of Economic Issues XLVI: 499-510.

Jurgens, M.H. Animal Feeding and Nutrition, 5th Edition. Dubuque, IA: Kendall/Hunt Publishing Company, 1978.

Kaase, G.H., M. Young, S. Klose, J. Paschal, W. Hanselka, M. Jupe. 2007. “Long-Term Financial Impact of Drought Management Strategies." Department of Agricultural Economics, Texas Cooperative Extension, Texas A\&M University. FARM Assistance Focus Report, February.

Kellems, R.O., and D.C. Church. Livestock Feeds and Feeding, 5th Edition. Upper Saddle River, NJ: Prentice Hall, 2002. 
Kulshreshtha, S.N., C.W. Grant, R. Marleau, and E. Guenther. 2003. "Canadian Droughts of 2001 and 2002." Technical Report. Saskatchewan Research Council.

Kusunose, Y., and T.L. Lybbert. 2014. "Coping with Drought by Adjusting Land Tenancy Contracts: A Model and Evidence from Rural Morocco." World Development (61): 114-126

Livestock Marketing Information Center. Spreadsheets, various workbooks. www.lmic.info. Accessed on various dates, 2013.

Lawson, D., and I. Kasirye. 2013. "How the Extreme Poor Cope With Crises: Understanding the Role of Assets and Consumption." Journal of International Development (25): 1129-43.

Leister, A.M., P. Paarlberg, and J. Lee. 2015. "Dynamic Effects of Drought on U.S. Crop and Livestock Sectors." Journal of Agricultural and Applied Economics 47(2): 261-284.

MacDonald, J.M. and M.E. Ollinger. 2001. "Scale Economies and Consolidation in Hog Slaughter: Reply." American Journal of Agricultural Economics 83(4): 1084-1086.

Maystadt, J.-F., and O. Ecker. 2014. "Extreme Weather and Civil War: Does Drought Fuel Conflict in Somalia through Livestock Price Shocks?" American Journal of Agricultural Economics (96): 1157-1182

McKinzie, L., P.L. Paarlberg, and I.P. Huerta. 1986. "Estimating a Complete Matrix of Demand Elasticities Using Pseudo Data." European Review of Agricultural Economics 13: 21-42.

Mwakaje, A.G. 2013. "The Impact of Climate Change and Variability on Agro-pastoralists' Economy in Tanzania." Environmental Economics (4): 30-38.

Paarlberg, P.L., A.H. Seitzinger, J.G. Lee, K.H. Mathews Jr. 2008. “Economic Impacts of Foreign Animal Disease." Economic Research Report No. 57.

Peel, D.S. 2013. "Impacts of Drought and Regional Change on Hay Production." Cow/Calf Corner, Oklahoma State University Extension. (April 8)

Ranjan, R. 2013. "Mathematical Modeling of Drought Resilience in Agriculture." Natural Resource Modeling (26): 237-58.

Richardson, J.W., J.L. Outlaw, G.M. Knapek, B.K. Herbst, and J.M. Raulston. 2013. "Economic Outlook for Representative Ranches Given the December 2013 FAPRI/AFPC Baseline." Texas A\&M University, FAPRI/AFPC Baseline AFPC Working Paper 13-4.

Rosen, S. 1987. “Dynamic Animal Economics," American Journal of Agricultural Economics 69 (3): 547-57.

Sanyal, K.K. and R.W. Jones. 1982. "The Theory of Trade in Middle Products." American Economic Review 72: 16-31.

Tonsor, G., and T. Marsh. 2007. “Comparing Heterogeneous Consumption in U.S. and Japanese Meat and Fish Demand." Agricultural Economics (37): 81-91.

United States Department of Agriculture, Economic Research Service. Costs of Production. Website: www.ers.gov. Accessed on various dates.

—. 2013. "U.S. Drought 2012: Farm and Food Impacts.” July 26.

United States Department of Agriculture, Farm Services Agency. 2015. "Disaster Assistance 2014 Farm Bill Fact Sheet. Livestock Forage Disaster Program." February.

_. 2015. "Disaster Assistance 2014 Farm Bill Fact Sheet. Livestock Indemnity Program." March.

United States Department of Agriculture, National Agricultural Statistics Service. Agricultural Statistics by State. Washington, D.C. Website: www.nass.usda.gov. Accessed April 14, 2013.

United States Department of Agriculture, World Agricultural Outlook Board. World Agricultural Supply and Demand Estimates (WASDE). Washington, D.C. Website: www. wasde.usda.gov. Accessed March 10, 2013.

United States Department of Commerce, U.S. Census Bureau. Annual Survey of Manufactures. Website: www:census.gov/manufacturaing/asm. Accessed May 14, 2012.

United States Drought Monitor. http://droughtmonitor.unl.edu. Accessed on various dates.

Verner, D., and C. Breisinger. Economics of Climate Change in the Arab World. The World Bank, Washington, D.C.: Report \#76368, 2013. 
Watkins, B. 2012. "The 2010 and 2011 Arkansas Drought Experience." AAEA Choices 27(3). Wallander, S., M. Aillery, D. Hellerstein, and M. Hand. 2013. "The Role of Conservation Programs in Drought Risk Adaptation." Economic Research Report No. 148.

Wang, T., S.C. Park, S. Bevers, R. Teague and J. Cho. 2013. "Factors Affecting Cow-Calf Herd Performance and Greenhouse Gas Emissions." Journal of Agricultural and Resource Economics 38(3): 435-456.

Westcott, P.C., and M. Jewison. Weather Effects on Expected Corn and Soybean Yields. Washington, DC: U.S. Department of Agriculture, Economic Research Service, FDS13 g-01, July 2013.

Young, M., D. Hale, C. Pfluger, J. Paschal, W. Hanselka, S. Klose, M. Jupe. 2007. "Drought Recovery in South Texas Ranches." Department of Agricultural Economics, Texas Cooperative Extension, Texas A\&M University. FARM Assistance Focus Report, March.

Young, M., J. Paschal, W Hanselka, S. Klose, M. Jupe. 2006. "Impact of Prolonged Drought on South Texas Ranches.” Department of Agricultural Economics, Texas Cooperative Extension, Texas A\&M University. FARM Assistance Focus Report, September.

Yu, T. and B.A. Babcock. 2010. Are U.S. Corn and Soybeans Becoming More Drought Tolerant? American Journal of Agricultural Economics 92(5): 1310-1323.

\section{Appendix}

\section{Potential Economic Effects of Continued Drought}

Additional analysis was conducted to assess the potential impacts of continued drought conditions that extend into a third year for crop sectors in the model. Shocks to crop yields for an assumed 2013 drought were estimated from state yields and the Drought Monitor, which indicated continued drought for the Central and Southern Plains states in the U.S. in 2013. Accordingly, the deviation from 2012 crop yields, as reported by NASS, compared to the longrun trend yield was used to calculate U.S. yield shocks by crop sector for 2013. While continued drought may result in intensified beef cattle slaughter relative to baseline expectations (Peel 2013), this exercise includes droughtinduced shocks to crop sectors alone in the third year of drought. Therefore, the results for an extended drought that spans three consecutive years in this Appendix simulation serves as a lower-bound estimate of potential prolonged drought effects that extend beyond the two-year drought included in this study, if drought-induced slaughter were to occur. The estimated yield shocks for a simulated 2013 drought in crop sectors include a 5\% decrease in winter wheat yield, a $3 \%$ decrease in spring coarse grain yield, a $5 \%$ decrease in soybean yield, as well as a $6 \%$ decrease in winter and spring forage in 2013.

Appendix Figures 1A through 3 illustrate the difference between key changes in finished beef prices, breeding herd inventories and cattle slaughter for normal weather conditions resuming in 2013 versus continued drought in crop sectors in 2013. Both the two-year drought and three-year drought scenarios are compared to baseline levels, while this discussion will focus on 


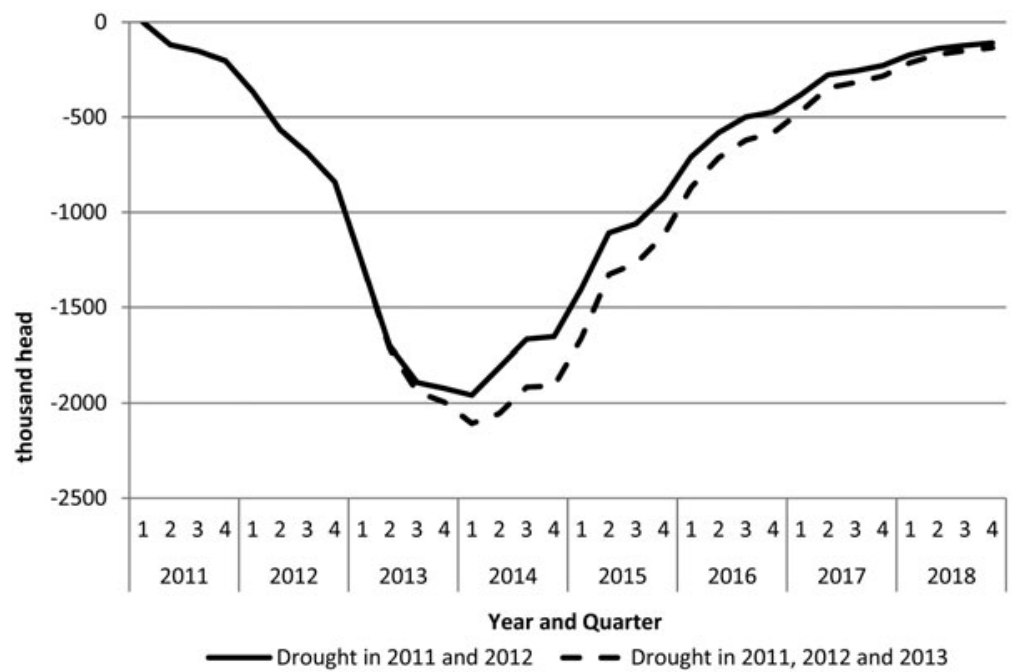

Figure 1. Comparison of change in U.S. beef cattle breeding herd inventories with continued drought

the difference between the two scenarios: first when drought occurs only in 2011 and 2012 versus when drought occurs in 2011, 2012 and 2013.

Given the presence of drought in only 2011 and 2012, crop prices begin to stabilize and remain near baseline levels in 2015, within 3 years of the drought. However, breeding herd inventories reach their lowest levels in the first quarter of 2014. Inventories begin to recover in the second quarter of 2014, but do not reach baseline levels by the end of the period of analysis (2018). This contributes to the increases in the prices of finished cattle, wholesale and retail beef as fewer calves are born and fewer animals are available throughout the beef supply chain in future periods as herd inventories remain below baseline levels. The overall impacts of continued drought in 2013 result in an amplification of the effects on key variables beginning in 2013 and causes an extension in the time it takes to return towards the baseline for the beef sector. As a result of extended drought pressure, herd size reductions are intensified causing increased tightening of cattle supplies throughout the beef supply chain (Figure 1A). Cattle slaughter is an average of 28 thousand head lower under the three-year drought versus two-year drought scenarios beginning in the second quarter of 2014 through the remainder of the period of analysis (Figure 2B). The decrease in slaughter cattle supplies causes further increases in steer prices relative to the case where drought does not continue in 2013 as illustrated in Figure 3C. The model-predicated finished cattle price is higher under the continued drought scenario beginning in the second quarter of 2014, and remains higher than 


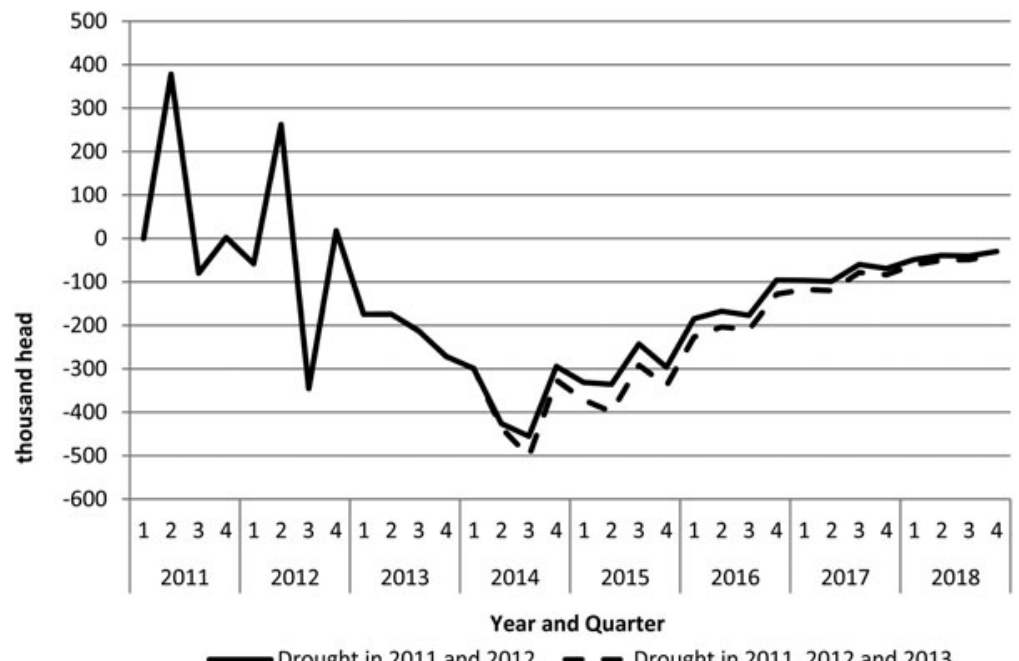

Figure 2. Comparison of change in U.S. cattle slaughter with continued drought

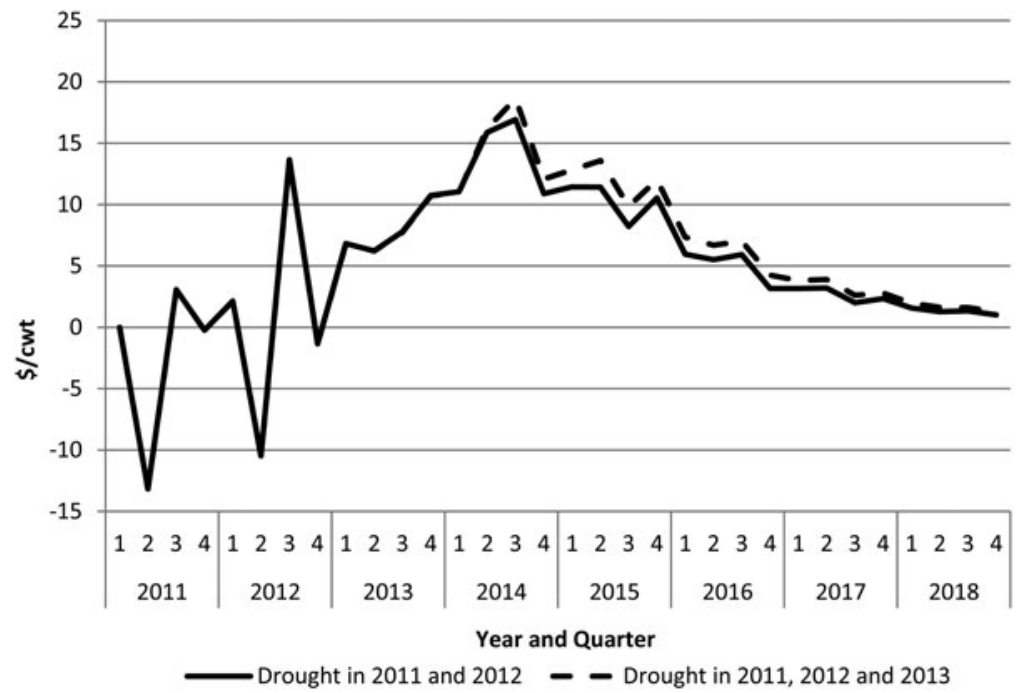

Figure 3. Comparison of change in U.S. finished cattle price with continued drought 
the no-drought scenario for the remainder of the timeframe of the analysis (Figure 3C).

The ability to consider multi-year drought in an integrated agricultural model that accounts for the intricacies of crop and livestock production and vertically integrated supply chains is a critical contribution of this research. By considering the effects of an extended drought that persists for an additional year, this appendix simulation further highlights the importance of considering the effects of multi-year drought in a dynamic framework, and provides additional evidence that the effects of drought are largely felt in subsequent years following the drought. 